\title{
Different Strategies of Compliment Responses Used by Iranian EFL Students and Australian English Speakers
}

\author{
Reza Mohajernia \\ Department of Applied Linguistics, Azad University, Isfahan, Iran \\ Hassan Solimani \\ Department of Applied Linguistics, Payame Noor University, 19395-3697, Tehran, Iran
}

\begin{abstract}
The advanced Iranian EFL students are capable of producing grammatically correct sentences, but they have a lot of gaps, lack of variety and form-function clashes in communication. Therefore, this pragmatic failure may specially be traced in the areas of speech acts. This paper investigates to explore the differences between the strategies of responses to compliments given by Iranian EFL students compared with Australian English speakers in terms of socio-cultural patterns. In line with the nature of the present research, a crosscultural one, 30 Australian English speakers and 30 Iranian EFL students were given a questionnaire consisting of two parts, each of which was composed of 8 open-ended questions. Based on the Chi- square inferential statistics the collected data were analyzed and interpreted and the results were obtained. The overall results suggested that some strategies of Compliment Responses (CRs) are cultural-specific like request interpretation "Qabel-Nadare" (I am glad to give it to you as a gift)" in Iranian culture and that there were various strategies of CRs which were used for different purposes by Iranian EFL students and Australian English speakers.
\end{abstract}

Index Terms - compliment responses, Iranian EFL students, socio-cultural patterns, speech acts

\section{INTRODUCTION}

Today, in researches related to second language learning and teaching, it is crucial to pay attention to the use of grammatical forms in the user's speech as well as to the ability to match structures with communicative functions. In other words, the need to use language that is appropriate to the social context has become a central focus for teachers and researchers (Kumaravadivelu.B, 2003). "The concept of communicative competence was introduced into applied linguistics in reaction to highly grammar-focused theories of language competence, which analyzes the nature of language as a system independently of its users" (Sari Luoma, 2009). After Lado and Carrolls'skills/components model (1960) was presented as the first model of language ability, the concept of Communicative Language Ability (CLA) has gone through a wide range of changes and reconceptualizations (Backman 1990). Lado and Carroll's model was ignorant of context for language use; this pitfall was remedied by Canale and Swain's framework (1980) through introducing the concept of sociolinguistic and strategic competence into their model. Later Bachman (1990) presented a model of CLA with three components. In the Bachman's model, psychophysilogical competence was incorporated, and also the concept of strategic competence was extended (Backman 1990). "The most frequently used communicative model in language testing today is Bachman and Palmer's (1996) model of language ability", which is a more elaborate model of CLA for language teaching and testing (Sari Luoma, 2009). Bachman and Palmer (1996) relabeled knowledge structure as Topical knowledge which refers to schemata about different topics that language user can benefit from in the context of language use. In their model strategic competence was also reconceptualized as a set of meta-cognitive structures (Backman 1990).

\section{A. Aspects of Speech Act Theory}

As far as language and function are concerned, speech act theory deals with the performance of different acts by utterances in an act of communication including locutionary, illocutionary, and perlocutionary acts. "Locutionary acts are simply the speech acts that have taken place, illocutionary acts are the real actions which are performed by an utterance, where saying equals doing, as in betting, plighting one's troth, welcoming and warning, and perlocutionary acts are the effects of the utterance on the listener, who, for example, accepts the bet or pledge of marriage" (Searle,J Austin, 1968, p 405-424).

\section{B. Types of Illocutionary Acts}

Some linguists have attempted to classify illocutionary acts into a number of categories or types. Machiko, quoting Searle (2003), enumerated five such categories: 
Representatives. The speaker asserts a proposition to be true, using such verbs as: affirm, believe, conclude, deny, and report.

Directives. The speaker tries to make the hearer do something, with such words as: ask, beg, challenge, command, dare, invite, insist, request.

Commissives. The speaker commits himself/herself to a (future) course of action, using verbs such as: guarantee, pledge, promise, swear, vow, undertake, warrant.

Expressives. The speaker expresses an attitude to or about a state of affair, using such verbs as: apologize, appreciate, congratulate, deplore, detest, regret, thank, welcome, and "compliments".

Declarations. The speaker alters the external status or condition of an object or situation, solely by making the utterance: "I now pronounce you man and wife".

\section{Compliments}

Holmes (1988, p.446) considered compliment as "a speech act which explicitly or implicitly attributes credit to someone other than the speaker, usually the person addressed, for some 'good' (possession, characteristic, skill, etc.), which is positively valued by the speaker and the hearer". Giving a compliment is a positive politeness strategy that enhances "the hearer's positive face" (Brown and Levinson, 1987, p 101). It is believed that complimenting "grease the social wheels" and thus serves as "social lubricants"; As a matter of fact complimenting is another speech act that implies the use of politeness strategies (Wolfson, 1983). Giving and responding to compliments is an important aspect of learning foreign languages for those who are from different cultural backgrounds (Neil Mercer, Janet Maybin, 2003). Spencer-Oatey $(2008$, p. 96) quoting pomerantz (1978) contends that people who are given compliments are faced with dilemma of having the strong inclination of fishing for compliments, and being under "the pressure of avoiding selfpraise". Patterned conversational moves can coerce people into gendered roles and enforce them. For example, a compliment offered to a woman on her appearance is part of the linguistic practice by which women are judged by their looks, while men are complimented on their actions and judged by their accomplishments Eckert, Penelope \& Sally (2003).

In an article by Chen-Hsin Tang \& Grace Qiao Zhang (2008), the findings demonstrated that Chinese participants prefer to use fewer "Accept" strategies and more Evade and Reject strategies, than their Australian counterpart; "that is the Chinese express appreciation for a compliment less than Australian and denigrate themselves more". Australians on the other hand prefer using explicit CRs more than Chinese participants. Another finding of the article is that the Chinese participants applied much less combined compliment response strategies than the Australians, "indicating that the Australians made more effort when responding to compliments". In another work by Golato (2005) focusing on sociocultural differences between Americans and Germans' compliment responses, she found that in their responses to compliment, Germans display "fewer rejections and disagreement" to complimenter than Americans, while the frequency of Americans' agreements and acceptance of compliments were higher than Germans. In this line of studies, Winnie Cheng (2003, p116) compares compliment responses of Hong Kong Chinese (HKC) with Native English Speakers (NES) and suggested that HKC do not use acceptance among the strategies of responding to a compliments, but NES are more willing to accept the compliment, even though they often turn it into sub-strategies of acceptance like, Praise Downgrades Or Shift Credit. With respect to Iranian strategies of compliment responses, in a contrastive study of compliment responses among male \& female teenage EFL learners Mohammad Ali Heidari, Mohsen Rezazadeh, Abbas Eslami Rasekh (2009) stated that "Iranian females use an indirect communication pattern of modest acceptance, and their "no" response to compliments means 'yes' which demonstrates consideration and politeness toward others". They suggested that "males prefer the use of the Accept response as a direct communication of acknowledgement", whereas females "consider that implicit CRs are as desirable, if not more desirable, than explicit CRs".

\section{Compliment and Compliment Responses Topics}

"In a series of articles, (e.g. Wolfson \& Manes 1980; Wolfson, Nessa 1981) it was noted that one of the most striking features of compliments in American English is their almost total lack of originality". Examining a corpus of approximately 700 compliments, they categorized compliment functions into 4 compliment actions and 5 compliment responses as follows (Herbert, 1990):

\section{E. Major Compliment Topics}

1) Appearance, 2) Possessions, 3) Performance/ skills/ abilities, and 4) Personality traits.

\section{F. Major types of Compliment response topics are}

1) Accept: Which is subcategorized as:

a) Appreciation token "Thanks/ Thank you"

b) Comment acceptance "Yeah, it's my favorite, too"

c) Praise upgrade "Really brings out the blue in my eyes, does not it?"

2) Mitigate: Which is subcategorized as:

a) Comment History "I bought it for trip to Arizona"

b) Shift Credit "My brother gave it to me/It really Knitted itself" 
c) Questioning or Request reassurance / repetition "Do you really like them?"

d) Return "So's yours"

e) Scale down / Downgrade "It's really quite old"

3) Reject "A: You look good and healthy B: I feel fat"

4) No acknowledgement (addressee responds with an irrelevant comment or gives no response)

5) Request Interpretation (Addressee interprets the compliment as a request such as: "You want to borrow this one too?" or "I am glad to give it to you as a gift"

\section{Methods AND Materials}

\section{A. Research Design and Hypothesis}

The present study is intended to describe strategies of responding to compliments. The study in this field provides the readers with the fact that there are languages and there are culture-based ways of performing a speech act, and these rays of culture in the first language (L1) may manifest itself while using the second language. The study investigates compliment behavior in Iranian EFL students in comparison with Australian English speakers. This study in particular investigates "responses to compliments". So the basic question of this study is "What are different strategies of Compliment Responses (CRs) given by Iranian EFL students compared with Australian English speaker in terms of socio-cultural patterns"?

Regarding the research question, the following null-hypothesis was formulated:

H0: There is no socio-culturally significant difference between strategies of Responding to Compliments used by Iranian EFL students and Australian English speakers.

\section{B. Participants}

Sixty subjects participated in this study. Participants in this study were thirty Australian native English speakers (AES), and thirty Iranian proficient speakers of English (IES). Australian native English speakers were all both native male and female living in Orange a town $206 \mathrm{~km}$ western of Sydney, Australia, and ranged in age from 22 to 55 . Iranian EFL students were both male and female as well, who were M.A. students in TEFL at Isfehan Azad University and ranged in age from 23 to 51 .

\section{Materials}

For the purpose of data collection, a questionnaire in accordance with the purpose of the experiment was prepared in English. It was composed of two parts: The first part included some demographic questions including the age, sex, level of education, and native language of the participants. and the second section (following Holmes, 1988) included 8 contextualized discourse situations concerning the strategies of responding to compliments which were technically designed regarding the research question to successfully elicit different strategies of responding to compliment, and were divided into following categories: Accept/ Mitigate/ Reject/ No acknowledgment/ and Request interpretation. In this section, situations were designed in a way that made it difficult to write anything socio-linguistically appropriate other than a responding to compliment as happening in daily language interactions.

\section{Procedures}

Among various pragmatic research methods which have been applied in studies on compliments, Manes and Wolfson (1981) argue that the ethnographic models, mostly in form of the dairy methods is the most reliable for collecting compliments (Andreas H. Jucker, Irma Taavitsainen, 2008). However, the questionnaire used in the present study is as well another ethnographic model for investigations about compliments which is a form of Discourse Completion Task (DCT) originally developed by Blum-Kulka (1982) and Oleshtain \& Blum-Kulka (1985) in which subjects are asked to respond to a given situation. "An example of this method is provided by Chen (1993) who used a discourse completion task to investigate cultural differences in compliment responses between speakers of Chinese and of American English. More recently, Schneider and Schneider (2000) have extended this line of research and used the same discourse completion task with speakers of Irish English and of German". (Andreas H. Jucker, \& Irma Taavitsainen, 2008, p 205). Many scholars who have conducted research in fields of Cross-cultural pragmatics have considered DCT as a form of data collection procedure with some main credits and also some discredits.(Shoshana Blum-Kulka, Juliane House, Gabriele Kasper, 1989). "Justified criticisms have been leveled at the DCT some labeling it an instrument that limits the capturing of authentic communication, and others making it look almost absolute. However, there are to date no other sociolinguistic data collection instruments that have as many administrative advantages as the DCT". (Billmyer \& Varghese, 2006). One great advantage of "this type of data collection is that the data elicited reflect the content of oral data despite its written form"; another point of advantage relates to the ease and practicality of data elicitation across cultures. (Klaus P. Schneider, Anne Barron, 2008). For the purpose of elicitation of the data in this study, the questions for Australian subjects were administered by a friend of mine "Micelle Clark", an Australia citizen who was accurately informed by the researchers how to deal with the task, but the tests for the other group were administered and conducted by the researchers themselves. During the test, the administrators were available to answer any question raised by the subjects. 


\section{E. Data Analysis}

In this part the focus of attention is on the analysis of data obtained through 8 open-ended questions concerning the difference between strategies of responding to compliments used by Iranian EFL students and Australian English speakers in terms of socio-cultural patterns. Table 1, displays 5 major categories of responding strategies to compliments, which are almost consistent in different cultures except their frequencies and the purpose behind their use.

TABLE I.

FREQUENCY OF MAIN STRATEGIES OF RESPONDING TO COMPLIMENT USED BY IRANIAN VS. AUSTRALIAN PARTICIPANTS

\begin{tabular}{|l|l|l|}
\hline Response Strategies & Iranian & Australian \\
\hline Reject & 9 & 18 \\
\hline Mitigate & 120 & 132 \\
\hline No acknowledge & 2 & 9 \\
\hline Accept & 91 & 121 \\
\hline Request Interpretation & 48 & 5 \\
\hline
\end{tabular}

Of course, it should be considered that a participant's response can consist of more than one simple utterance of accepting or rejecting or other types of responses; for example, it could be Accepting + Mitigate. On the face of it, the strategies of responding to complimenting used by the two cultural groups under the study do show discrepancies in most of the columns except for the second column i.e. Mitigate in table 1, but this is a premature judgment unless we go into detailed information.

TABLE II.

COMPUTATION OF $\mathrm{X}^{2}$

\begin{tabular}{|l|l|l|l|l|l|l|}
\hline $\mathrm{R}$ & $\mathrm{C}$ & $\mathrm{O}$ & $\mathrm{E}$ & $\mathrm{O}-\mathrm{E}$ & $(\mathrm{O}-\mathrm{E}) 2$ & $£(\mathrm{O}-\mathrm{E}) 2 / \mathrm{E}$ \\
\hline 1 & 1 & 91 & 103.13 & -12.13 & 147.136 & 1.42670 \\
\hline 2 & 2 & 120 & 122.59 & -2.59 & 6.708 & 0.05471 \\
\hline 3 & 1 & 9 & 13.13 & -4.13 & 17.056 & 1.29900 \\
\hline 4 & 2 & 2 & 5.35 & -3.35 & 11.225 & 2.09813 \\
\hline 5 & 1 & 48 & 25.78 & 22.22 & 493.728 & 16.15159 \\
\hline 1 & 2 & 121 & 108.86 & 12.14 & 147.379 & 1.35383 \\
\hline 2 & 1 & 132 & 129.40 & 2.6 & 6.76 & 0.05224 \\
\hline 3 & 2 & 18 & 13.86 & 4.14 & 17.139 & 1.23658 \\
\hline 4 & 1 & 9 & 5.64 & 3.36 & 11.289 & 2.00159 \\
\hline 5 & 2 & 5 & 27.21 & -22.21 & 493.284 & 18.1398 \\
\hline
\end{tabular}

In order to deal with the above data, Chi-square test was conducted for the analysis of the estimated frequencies. Table. 2 shows the estimated Chi-square for the given data is $x^{2}(P=0.05, d f=4)=43.814$, and from the tabulated $x^{2}$ values (see appendix 2), it is evident that at the 0.05 level of significant with 4 degree of freedom critical value of $x^{2}$ is equal to 9.487. As it is obvious, not only our calculated $x^{2}$ is greater than $x^{2}$ value for probability of 0.05 ,but also it exceeds even the tabulated $x^{2}$ value for 0.001 probability which is equal to 18.47. So we conclude that there is a highly significant departure from the null hypothesis, and this gross difference indicates that our null hypothesis is firmly rejected i.e. we have very strong evidence that the results of the Chi-square test reveal socio-cultural differences between strategies of responding to compliment by Iranian EFL students and Australian English speakers in this study.

\section{F. Content Analysis}

Response strategies of compliments (See Table 1) consist of 5 major categories, 2 of which (Accepting and Mitigate) have sub-categories, i.e. Accepting consists of three sub- categories including Appreciation token, Praise up grade, and Comment acceptance. The strategy of Mitigate as well is composed of five sub- strategies including Comment history, Scale down, Shift credit, Return, and Question reassurance. Finally three other major strategies which do not have any sub-divisions are Rejecting, No Acknowledgment, and Request interpretation. The distributions and frequencies of the above strategies will be investigated in the following section.

\section{Strategy of Accepting.}

As Table 1 displays, the total number of Accepting strategies used by Iranian is lower than those of Australian (Iranian=91, Australian=121) indicating Iranians' less willingness to accept compliments in comparison with Australian.

Examples from the data:

Example 1

You have used a perfume you have bought recently.

Your friend: That smells wonderful!

You: Thanks, That's kind of you.

(Accept/shift credit, from Iranian responses)

Example 2

You are showing your new stereo to your friend.

Your friend: that's terrific!

You: yeah, the speakers really make a big difference to the sound. 
(Accept/praise upgrade from Australian responses).

\section{Strategies of Mitigating.}

As Table 1 shows, the total number of strategy of Mitigating used by two groups is almost the same but this does not seem to be comprehensive. When we take a glance at the frequencies and percentages of sub-divisions of Mitigating strategy (see Table 3), we will come up with different conclusions. In fact, even though Iranian and Australian use of Mitigating strategy is not so different, when it comes to 5 sub-divisions of this strategy, real differences become evident and we might claim that Australians prefer to use strategy of Comment History more, whereas Iranian show more preference to use the other three sub-strategies of Mitigating nearly twice as much as of Australian which may show more power and presence of modesty and humility in cornerstones of Iranian culture in comparison with that of Australians. Examples from the data:

Example 3

You are at a party with your friends.

Your friend: I like your suit. It's very smart!

You: Yours looks nice too.

(Mitigate/return, from Australian responses)

Example 4

You have got an A score in your exam because the question were very easy.

Your friend: hey, I really like this color. I wish I had seen this carpet when I picked out mine!

You: no, I was just lucky with the questions.

(Rrejec+Mitigate/shift credit \& scale down, from Iranian responses)

TABLE III.

FREQUENCY OF RESPONDING STRATEGIES TO COMPLIMENT USED BY IRANIAN VS. AUSTRALIAN PARTICIPANTS

\begin{tabular}{|l|l|l|}
\hline Strategies of Responding to & Frequency & Australian \\
\cline { 2 - 3 } Compliments & Iranian & 64 \\
\hline Appreciation token & 59 & 39 \\
\hline Comment acceptance & 20 & 18 \\
\hline Praise upgrade & 12 & 38 \\
\hline Comment history & 14 & 16 \\
\hline Scale down & 30 & 19 \\
\hline Shift credit & 26 & 36 \\
\hline Return & 34 & 23 \\
\hline Question reassurance & 16 & 9 \\
\hline No Acknowledgment & 2 & 18 \\
\hline Rejecting & 9 & 5 \\
\hline Request interpretation & 48 & \\
\hline
\end{tabular}

\section{Strategy of No Acknowledgement and Strategy of Reject.}

As it is observed in Table3, the differences between frequencies of these two responding strategies for two groups are not so much outstanding, consequently we can claim that both groups do not seem to be willing to make so much use of these strategies. Examples from the data:

Example 5

You have bought a new carpet and you have invited your friend for dinner.

Your friend: hey, I really like this color. I wish I had seen this carpet when I picked out mine!

You: Too bad may be next time.

(Kind of Response Strategy: No acknowledgement)

Example 6

You have got an A score in your exam because the question were very easy.

Your friend: hey, I really like this color. I wish I had seen this carpet when I picked out mine!

You: no, they just asked the questions I knew.

(Kind of Response Strategy: Reject)

4. Strategy of Request Interpretation.

The most interesting part of the present research is probably related to strategy of Request interpretation. As it is shown in the Table 3, the frequency differences between two groups are evidently outstanding and perhaps it can be claimed that it is mostly the presence of this strategy that causes the rejection of the research null hypothesis. As it is observable in the Table 3, the frequency of this strategy used by Iranian EFL students is 48, whereas this frequency for Australian is equal to 5. But more interesting than their frequencies is the fact that even the very few cases of this strategy among Australian refer to concepts different from those of Iranians. In other words, each group has a different purpose and concept behind making use of this strategy. In order to shed some light on this issue, we present some examples of using this strategy by two groups. Examples from the data:

Example 7:

1. You are showing your new stereo to your friend.

Your friend: That's really a terrific stereo. 
You: You can take it as a gift "Qabel-nadare"

The above example is related to Iranian EFL students, but the following one is related to Australians.

Example 8:

2. You are showing your new stereo to your friend.

Your friend: That's really a terrific stereo.

You: Do you want to hear a "demo"

Reflecting on the above examples, we can clarify the differences between concepts and purposes of each group for using this strategy. In fact, use of this strategy by Iranian and offering the ownership of their properties as a gift in the Persian phrase of "Qabel-Nadare" means showing affection to complimenter whereas by using this strategy, Australians never ever offer the ownership of their properties and just at most offer using that property. We mentioned earlier that there were only 5 cases of applying this strategy by Australian out of 285 responses besides, in most cases where Iranian EFL students used this strategy, it was found that Australian used other strategies instead.

\section{CONCLUSION AND PEDAGOGICAL IMPLICATIONS}

The general results obtained regarding these strategies revealed numerous and deep dissimilarities and also some similarities between strategies of responding to compliments applied by Iranian EFL students and Australian English speakers in terms of socio-cultural patterns. Results emphasized that total number of Accepting strategies used by Iranian are lower than those of Australian indicating Iranians' less willingness to accept compliments in comparison with Australian English speakers; nevertheless, it was also discovered that the differences between Accepting strategies used by the two groups are mainly carried by the two Accepting sub-strategies i.e., Comment Acceptance and Praise Upgrade that implies both Iranian and Australian express thanking in response to compliment but Iranian prefer to a great extent not to express any verifying comment on the features, properties, or traits about which they have been complimented.

With regard to strategies of Mitigate, it was found that even though Iranian and Australians' use of strategies of Mitigate are not so different, with respect to 5 sub-divisions of this strategy, real differences becomes evident and it can be claimed that Australians prefer to use strategy of Comment history more than other ones, whereas Iranian show more preference to use other three real sub-strategies of Mitigating nearly twice as much as of Australian which may show more power and presence of modesty and humility in cornerstones of Iranian culture in comparison with that of Australians. This is supported as well by the findings of Briallen Davis (2008) pertaining to compliment responses among Australian female who suggests that nearly around $40 \%$ of participants offered the purchase history of the complimented article i.e. the responding strategy of Comment history after their expression of thanks.

Finally, concerning the findings related to the responding strategy of request interpretation, it might be indicated that $\% 17.77$ of Iranian EFL students' responses were of this type believing that appearing generous will maintain and enhance the face and image, whereas Australians only expressed $\% 1.75$ of their compliment responses using this strategy. According to the results, it was found that there were only 5 cases of using this strategy by Australians out of 285 responses and in most cases where Iranian EFL students used this strategy, it was observed that Australian used other strategies instead since it may be claimed that the reason behind this few number of this strategy among Australian is that such an strategy with the same concept among Iranian is not existent in most English spoken contexts like Australia.

The findings of this study will have some implications for teachers, materials developers, and researchers. This study indicates that some strategies of responding to compliments are unique while others are nearly universal. This implies that teachers and materials designers should underscore these similarities and discrepancies among languages. Language teachers and material developers should sensitize learners to a variety of linguistic forms. Besides, foreign language classrooms should benefit from the findings of such cross-cultural studies some of which are rarely carried out and language teachers should make their students well aware of the differences in speech acts between L1 and L2 and assist them to notice the gaps between their own production and that of native speakers. Above all, the findings drawn from these studies and the cross-cultural similarities and varieties recorded in the study should be reconsidered, clarified, and presented in the classroom.

\section{ACKNOWLEDGEMENT}

We would like to thank our research assistant, our friend, Micelle Clark, one of the citizens of Australia for his help with the data collection. We also especially want to thank all the participants for their high degree of involvement in this project.

\section{APPENDIX A}

Personal information:

Native language:

Education:

Instruction
Gender:

Email:
Age: 
Please read the following 8 situations and write a response in the blank after "you". The questions are meant to investigate how you "respond to a compliment" given by your friends and relatives in the real world in your daily conversations.

1. You have helped your friend with his her homework.

Your friend: You're the best and kindest friend I have ever had.

You:

2. You have used a perfume you have bought recently.

Your friend: Hey, guy this is dynamite!

You:

3. You are at a party with your friends.

Your friend: I like your suit. It's very smart!

You:

4. You have bought a new carpet and you have invited your friend for dinner.

Your friend: hey, I really like this color. I wish I had seen this when I picked up mine!

You:

5. You have got an A score in your exam because the question were very easy.

Your friend: It seems that you are really intelligent and hard working.

You:

6. You are showing your new stereo to your friend.

Your friend: That's really a terrific stereo.

You:

7. After the competition in a tennis game.

Your friend: You played a good game of tennis.

You:

8. You are having on a pair of jeans walking in the street and suddenly you ran into a friend of yours.

Your friend: Hey, these jeans really go with you.

You:

APPENDIX B

\begin{tabular}{|c|c|c|c|c|c|}
\hline \multicolumn{6}{|c|}{ TABLE OF $\mathrm{X}^{2}$ VALUES } \\
\hline $\begin{array}{l}\text { Degrees of } \\
\text { Freedom }\end{array}$ & 0.99 & 0.95 & 0.05 & 0.01 & 0.001 \\
\hline 2 & 0.020 & 0.103 & 5.99 & 9.21 & 13.82 \\
\hline 3 & 0.115 & 0.352 & 7.82 & 11.35 & 16.27 \\
\hline 4 & 0.297 & 0.711 & 9.49 & 13.28 & 18.47 \\
\hline 7 & 1.239 & 2.167 & 14.07 & 18.48 & 24.32 \\
\hline 8 & 1.646 & 2.733 & 15.51 & 20.09 & 26.13 \\
\hline 9 & 2.088 & 3.325 & 16.92 & 21.67 & 27.88 \\
\hline 10 & 2.558 & 3.940 & 18.31 & 23.21 & 29.59 \\
\hline 11 & 3.05 & 4.58 & 19.68 & 24.73 & 31.26 \\
\hline 16 & 5.81 & 7.96 & 26.30 & 32.00 & 39.25 \\
\hline 17 & 6.41 & 8.67 & 27.59 & 33.41 & 40.79 \\
\hline 18 & 7.02 & 9.39 & 28.87 & 34.81 & 42.31 \\
\hline 19 & 7.63 & 10.12 & 30.14 & 36.19 & 43.82 \\
\hline 20 & 8.26 & 10.85 & 31.41 & 37.57 & 45.32 \\
\hline 21 & 8.90 & 11.59 & 32.67 & 38.93 & 46.80 \\
\hline 22 & 9.54 & 12.34 & 33.92 & 40.29 & 48.27 \\
\hline 23 & 10.20 & 13.09 & 35.17 & 41.64 & 49.73 \\
\hline 24 & 10.86 & 13.85 & 36.42 & 42.98 & 51.18 \\
\hline 25 & 11.52 & 14.61 & 37.65 & 44.31 & 52.62 \\
\hline 26 & 12.20 & 15.38 & 38.89 & 45.64 & 54.05 \\
\hline
\end{tabular}




\section{REFERENCES}

[1] Andreas H. Jucker, \& Irma Taavitsainen. (Ed.). (2008). Speech Acts in the History of English. University of Zurich.

[2] Bachman, L. (1990). Fundamental considerations in language testing. Oxford: Oxford University Press.

[3] Bachman, L. F. \& Palmer, A .S. (1996). Language testing in Practice. Oxford: Oxford University Press.

[4] Billmyer \& Varghese. (2006). Investigating instrument-based pragmatic variability: effects of enhancing discourse completion tests, Online ISSN 1477-450X - Print ISSN 0142-6001 Copyright () 2011 Oxford University press.

[5] Blum-Kulka, S. (1982). Learning how to say what you mean in a second language. Applied Linguistics 3, 29-59.

[6] Briallen Davis (2008). Compliment responses across gender. Griffith Working Papers in Pragmatics and Intercultural Communication 1, 2, 76-87.

[7] Brown, P., \& Levinson, S. C. (1987). Politeness: Some universals in language use. Cambridge, UK: Cambridge University Press.

[8] Chen-Hsin Tang \& Grace Qiao Zhang. (2008). A contrastive study of compliment responses among Australian English and Mandarin Chinese speakers. Department of Foreign Languages, Kaohsiung County 82144, Taiwan.

[9] Chen, R. (1993). Responding to compliments: A contrastive study of politeness strategies between American English and Chinese speakers. Journal of Pragmatics, 20: 49-75.

[10] Eckert, Penelope, \& Sally. (2003). Language and gender. New York: Cambridge University Press.

[11] Golato, A. (2005). Compliments and Compliment Responses: Grammatical Structure and Sequential Organization. London: John Benjamins.187-190

[12] Heidari, M. A., Rezazadeh, M., \& Eslami Rasekh, A. (2009). A Contrastive Study of Compliment Responses among Male \& Female Iranian Teenage EFL Learners. The International Journal of Language Society and Culture. 29, 18-19

[13] Herbert, R. K. (1990). Sex-based differences in compliment behavior. Language in Society 19, 201_224.

[14] Holmes, J. (1988). Paying compliments: A sex preferential positive politeness strategy. Journal of Pragmatics 12 (3), 445-465.

[15] Klaus, Schneider, \& Barron. (2008). Variational pragmatics: A focus on regional varieties in pluricentric languages. John Benjamins Publishing Company. The Netherlands.

[16] Kumaravadivelu. (2003), Beyond Methods: Macrostrategies for Language Teaching, Yale University Press New Haven and London.

[17] Machiko. A (2003). learning to request in a second language: A study of child interlanguage pragmatics. UK: Multilingual Matters. 6-7

[18] Manes, J. And Wolfson, N. (1981). The Compliment formula. In F. Coumas (ed), Conversational Routine: Explorations in Standardized Communication Situations and Prepatterned Speech. The Hague: Mouton Publishers. 115-132.

[19] Using English from conversation to canon. (2003) .Open University,.Neil Mercer, Janet Maybin,.32

[20] Olshtain, E., \& Blum-Kulka, S. (1985). Degree of approximation: Nonnative reactions to native speech act behavior. In S. Gass \& C. Madden. (Eds.) Input in second language acquisition. Rowley, MA: Newbury House.

[21] Pomerantz, A. (1978). "Compliment responses: Notes on the cooperation of multiple constraints". In J. Schenkein (Eds.), Studies in the Organization of Conversational Interaction (pp. 79-112). New York/ San Francisco/ London: Academic Press.

[22] Sari Luoma. (2009). Assessing Speaking, United Kingdom, Cambridge University Press, 5th printing

[23] Searle, J -Austin, (1968).On locutionary and Illocutionary Acts. The Philosophical Review 77,405-424.

[24] Shoshana Blum-Kulka, Juliane House, Gabriele Kasper. (1989) .Cross-cultural pragmatics: requests and apologies. Ablex Pub. Corp.

[25] Spencer-Oatey, H. (Ed.), (2008).Culturally Speaking Culture, Communication and Politeness Theory. London. Continuum International Publishing Group. 96.

[26] Winnie Cheng. (2003). Intercultural conversation. The Hong Kong Polytechnic University.116.

[27] Wolfson, N., \& Manes, J. (1980). The compliment as a social strategy. Papers in Linguistics: International Journal of Human Communication, 13(3), 410-451.

[28] Wolfson,N. \& Nessa. (1981). Compliments in cross-cultural perspectives. TESOL Quarterly 15 (2): 117_123.

[29] Wolfson, N. (1983). 'An empirically based analysis of complimenting in American English'. In N. Wolfson and E. Judd (Eds.), Sociolinguistics and Language Acquisition. Rowley, MA: Newbury House. 82-95

Reza Mohajernia is a part time professor at Medical Science University, received his M.A. in applied linguistics from Azad Isfahan University in 2005, currently preparing for Ph. D. Entrance Exam. His special interests are SLA issues in general and sociolinguistics in particular.

Hassan Soleimani is an assistant professor of applied linguistics at Payame Noor University, Iran. Dr. Soleimani received his Ph. D. in applied linguistics from Isfahan University in 2008. He has authored several books the last one entitled Non-parametric Statistics for Applied Linguistics Research in 2010. He is the author of several articles and has presented some papers in international conferences. His special interests are SLA issues in general and research and statistics in particular. 